\title{
Inclusão e participação nos cuidados ao filho pré-termo na unidade neonatal: percepções paternas
}

Inclusion and participation in the care of the preterm infant at neonatal unit: paternal perceptions Inclusión y participación en los cuidados al hijo prematuro en la unidad neonatal: percepciones paternas

\section{Eilane CarvalhoI, Patrícia Pereira de Oliveira Cercal Mafra' ${ }^{\text {II }}$ Lidiane Ferreira Schultz ${ }^{\text {III }}$ Beatriz Schumacher ${ }^{\mathrm{IV}}$, Luana Cláudia dos Passos Aires ${ }^{\mathrm{V}}$}

\begin{abstract}
Resumo: Objetivo: descrever as percepções paternas sobre a sua inclusão e participação nos cuidados durante a internação do seu filho pré-termo em uma Unidade Neonatal. Método: estudo descritivo com abordagem qualitativa realizado em uma maternidade pública do norte de Santa Catarina. Os dados foram coletados de junho a agosto de 2017, por meio de entrevistas semiestruturadas com 11 pais. Utilizou-se a análise temática para analisar os dados. Resultados: emergiram quatro categorias: o ser pai de um recém-nascido pré-termo e o impacto na dinâmica familiar; o primeiro toque paterno; tornar-se pai: a participação e a inclusão do pai nos cuidados com o filho internado; a equipe de saúde para o protagonismo paterno. Considerações finais: as condições clínicas do recém-nascido e a relação interpessoal com a equipe de saúde influenciam na participação do pai nos cuidados, sendo necessário promover o empoderamento paterno na Unidade Neonatal.

Descritores: Recém-nascido prematuro; Unidades de terapia intensiva neonatal; Método Canguru; Enfermagem neonatal; Relações pai-filho
\end{abstract}

\begin{abstract}
Aim: to describe paternal perceptions about their participation and inclusion in the care of their preterm infants staying at a Neonatal Unit. Methods: a descriptive study with qualitative approach performed at a public maternity that is a reference hospital in Kangaroo Care, in the north of Santa Catarina, Brazil. The data were collected between June and August of 2017 through semi-structured interviews conducted with 11 fathers.
\end{abstract}

\footnotetext{
I Enfermeira. Graduada pela Faculdade IELUSC. Unidade Neonatal - Hospital Dona Helena. Joinville/SC - Brasil. E-mail: eilanecarvalho.nane@gmail.com ORCID 0000-0003-2271-1578

II Enfermeira. Graduada pela Faculdade IELUSC. Maternidade Darcy Vargas. Joinville/SC - Brasil. E-mail: pati.mfr87@gmail.com ORCID 00000003-0108-8262

III Enfermeira. Mestre em Enfermagem pela UNG. Docente Adjunta do Curso de Graduação em Enfermagem da Faculdade IELUSC. JoinvilleSC/Brasil. E-mail: lidiane.schultz@ielusc.br ORCID 0000-0001-5146-7442

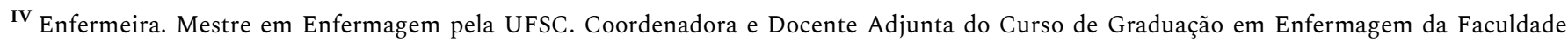
IELUSC. Joinville/SC - Brasil. E-mail: beatriz.schumacher@ielusc.br ORCID 0000-0002-6039-1926

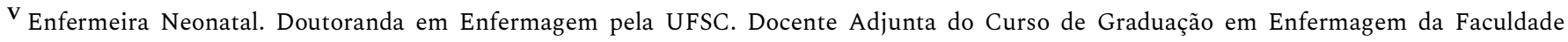
IELUSC. Joinville/SC - Brasil. E-mail: luana.aires08@gmail.com ORCID 0000-0003-3043-2018
} 
Thematic analysis was used to analyze the data. Results: four categories were identified: to be a father of a preterm newborn and its impact on the family dynamic; the first paternal touch; becoming a father; the participation and inclusion of the father in the care of his hospitalized infant; the healthcare team actions to build a paternal leading role. Final considerations: the clinical condition of a preterm newborn and the interpersonal relationship with the healthcare team influence the paternal participation on the infant care. Therefore, it is necessary to promote paternal empowerment at the Neonatal Unit.

Key words: preterm newborn; Neonatal Intensive Care Unit; Kangaroo care; Neonatal nursing; father-son relationships

Resumen: Objetivo: describir las percepciones de los padres sobre su inclusión y participación en los cuidados durante la internación de su hijoprematuro en una Unidad Neonatal. Método: estudio descriptivo,de perspectiva cualitativa, realizado en una maternidad pública del norte de Santa Catarina. Los datos fueron recolectados entre junio y agosto de 2017, por medio de entrevistas semiestructuradas con 11 padres de familias. Se utilizó el análisis temático para analizar los datos. Resultados: surgieron cuatro categorías: el ser padre de un recién nacido prematuro y el impacto en la dinámica familiar; el primer toque paterno; convertirse padre: la participación y la inclusión del padre en el cuidado del hijo internado; el equipo de salud para el protagonismo paterno. Consideraciones finales: las condiciones clínicas del recién nacido y la relación interpersonal con el equipo de salud influencian la participación del padre en los cuidados, lo que revela ser necesario promover el empoderamiento paterno en la Unidad Neonatal.

Descriptores: Recién nacido prematuro; Unidades de terapia intensiva neonatal; Método de canguro; Enfermería neonatal; Relaciones padre-hijo

\section{Introdução}

Aproximadamente 15 milhões de recém-nascidos $(\mathrm{RN})$ pré-termos nascem anualmente no mundo, perfazendo uma incidência de um para cada dez nascimentos. ${ }^{1-2} \mathrm{~A}$ prematuridade é a segunda causa de mortalidade infantil, sendo considerada um problema de saúde pública mundial. ${ }^{1-2}$

A Unidade Neonatal (UN) é um setor crítico, com RN que necessitam de assistência contínua, especializada e criteriosa. O nascimento de um filho pré-termo é, geralmente, uma experiência atípica e imprevisível. O apoio, o vínculo, a compreensão e as intervenções planejadas pela equipe multiprofissional da UN são fundamentais durante a trajetória de internação e cuidado ao RN e família, proporcionando um ambiente favorável para que os pais desempenhem seu papel e função como protagonistas deste cuidado. ${ }^{1,3-4}$ 
No Brasil, a presença da família no processo de internação de um filho é um direito assegurado pelo Estatuto da Criança e do Adolescente (ECA) e a sua participação nos cuidados deve ser favorecida, incentivada, facilitada e ensinada pela equipe de enfermagem, independente da complexidade clínica do paciente. ${ }^{3}$ Neste contexto, a participação familiar de forma ativa nos cuidados com o filho tem como uma das finalidades, garantir a criação do vínculo afetivo, sendo a atuação paterna tão importante quanto a materna. ${ }^{1,5-6}$

O Ministério da Saúde (MS) busca garantir a inclusão paterna nos cenários de cuidado a partir da elaboração, implantação e implementação de estratégias, programas e políticas públicas, destacando-se: o pré-natal do parceiro; ${ }^{7}$ o cumprimento da Lei $\mathrm{n}^{\circ} 11.108$ de $2005,{ }^{8}$ que garante a presença de um acompanhante de livre escolha da mulher durante todo o período de trabalho de parto, parto e pós-parto imediato para o parto; além do livre acesso dos pais na UN por meio do Método Canguru (MC). ${ }^{1}$

Estas conquistas relacionadas ao aprimoramento das Políticas Públicas de Saúde se devem a transformação cultural do cuidado paterno. Anteriormente, o parto e nascimento era considerado um evento exclusivamente feminino, no qual a participação do pai era atribuída ao seu papel de provedor do lar e nos últimos anos o conceito de paternidade tem se modificado. O ingresso da mulher no mercado de trabalho também exerceu influência neste processo, sendo necessária a divisão das atividades domésticas relacionadas ao lar e aos filhos. ${ }^{9}$ Antes mesmo do nascimento, o pai encarrega-se do seu novo papel na sociedade, o que inclui transformações, mudanças e responsabilidades que irão consolidar o vínculo pai-filho. ${ }^{4,10} \mathrm{E}$ quando o nascimento do filho é antecipado, o homem pode não estar preparado para aproximar-se, realizar os cuidados e vivenciar as demandas e novas dinâmicas familiares. , $^{4-10}$

É relevante pesquisar, estudar e refletir sobre a temática, sendo primordial para a equipe de enfermagem conhecer os fatores preditores para a construção da relação afetiva pai e filho, que pode favorecer positivamente na saúde do neonato de imediato e até a vida adulta. Os pais 
Inclusão e participação nos cuidados ao filho pré-termo na unidade neonatal: percepções.... | 4

apresentam melhor enfrentamento na internação prematura de seu filho quando são incluídos precocemente nos cuidados e as mães sentem-se mais confiantes e menos estressadas. ${ }^{11-13}$

Diante deste contexto, e considerando a Política do $\mathrm{MC}^{1}$ e as portarias $\mathrm{n}^{\circ} 930^{14}$ e $\mathrm{n}^{\mathrm{o}}$ $3.389^{15}$ para a participação dos pais e a importância para o cuidado humanizado e integral com o RN, emerge a seguinte questão de pesquisa: Quais são as percepções do pai relacionadas à sua participação e inclusão no cuidado durante a internação do seu filho pré-termo na Unidade Neonatal? Assim, o objetivo desse estudo foi descrever as percepções paternas sobre a sua inclusão e participação nos cuidados durante a internação do seu filho pré-termo em uma Unidade Neonatal.

\section{Método}

Pesquisa descritiva com abordagem qualitativa, realizada em uma maternidade pública do norte do Estado de Santa Catarina (SC), referência estadual para o MC desde 2013.

Participaram do estudo 11 homens-pais de bebês pré-termos internados na UN da referida maternidade no período de junho a agosto de 2017, que dispões de 10 leitos de Unidade de Terapia Intensiva Neonatal (UTIN), 14 leitos de Unidade de Cuidado Intermediário Convencional (UCINCo) e três leitos de Unidade de Cuidado Canguru (UCINCa). Utilizou-se como critério de inclusão: pai de recém nascido pré-termo, presente na UN no momento de coleta dos dados da pesquisa e maior de 18 anos de idade. Por se tratar de uma maternidade de referência, muitos pais não conseguiam visitar seus filhos com relativa frequência, por trabalharem e residirem em municípios distantes. Sendo assim, foi identificado junto a equipe, pais que conseguiam estar mais vezes presentes na Unidade, prestando os cuidados com seu filho. Como critérios de exclusão: pai de filho com síndromes, malformações congênitas e outras doenças genéticas. 
Para a coleta de dados foi realizada uma entrevista semiestruturada a partir de um roteiro-guia, com perguntas abertas e fechadas que contemplavam os dados socioeconômicos dos participantes para a caracterização, bem como as percepções sobre como foi ter um filho pré-termo, como ocorreu o processo de internação do bebê e a inclusão do pai nos cuidados com o seu filho. No intuito de garantir a qualidade dos dados foi realizado teste piloto com três homens-pais em uma UN de outra instituição. Não houve a necessidade de modificar o instrumento, no entanto estes pais não foram incluídos no estudo.

As entrevistas foram realizadas em uma sala na $\mathrm{UN}$, garantindo um ambiente reservado e privativo, com o mínimo de interferências externas, sendo todas audiogravadas e transcritas na íntegra, com duração média de 30 min. A abordagem aos pais foi realizada em turnos aleatórios, por conveniência, atendendo aos plantões diurnos e noturnos, sem a realização de contato prévio. A coleta de dados foi finalizada ao ser atingida a saturação dos mesmos. ${ }^{16}$ Os dados foram interpretados a partir da análise do tipo temática seguindo as etapas: pré-análise, exploração do material e tratamento-interpretação. ${ }^{17}$

Os princípios éticos que nortearam a pesquisa foram garantidos de acordo com a Resolução 466/2012. O projeto foi aprovado pelo Comitê de Ética em Pesquisa (CEP) do Instituto Superior e Centro Educacional Luterano de Santa Catarina - Bom Jesus (IELUSC), com o parecer substanciado sob número de protocolo 2.071.706.

\section{Resultados e discussão}

Foram entrevistados 11 pais com idade entre 19 e 36 anos, com predomínio de: escolaridade ensino médio completo (quatro); estado civil casados (oito); residentes em JoinvilleSC (oito); religião evangélica (sete); e que vivenciavam pela primeira vez o nascimento do seu primeiro filho (sete). Quanto a ocupação profissional dos pais variou nas mais diversas áreas de atuação, sendo elas da área da indústria, comércio, construção civil, empresarial ou autônomo e 
Inclusão e participação nos cuidados ao filho pré-termo na unidade neonatal: percepções.... | 6

com renda familiar de um a cinco salários mínimos. O peso do nascimento dos RN variou entre $590 \mathrm{~g}$ e $1985 \mathrm{~g}$ e a idade gestacional, de 25 a 35 semanas.

Após a coleta, transcrição e análise dos dados emergiram quatro categorias temáticas: o ser pai de um recém-nascido pré-termo e o impacto na dinâmica familiar; o primeiro toque paterno; tornar-se pai: a participação e a inclusão do pai nos cuidados com o filho internado; a equipe de saúde para o protagonismo paterno.

\section{O ser pai de um recém-nascido pré-termo e o impacto na dinâmica familiar}

Nesta pesquisa, os participantes relataram não saber do risco para o parto e nascimento do filho prematuramente, embora alguns informaram que tinham conhecimento sobre comorbidades da mulher que pudessem desencadear o trabalho de parto e o parto antecipadamente.

O nascimento antecipado do filho e sua internação na UN são vividos pelo pai de maneira traumática, sendo evidenciados pelos relatos de não pretender ter outros filhos, de sentir-se despreparados, inseguros, assustados e com medo.

[...] foi um tremendo de um susto, tudo aconteceu muito rápido [...].(P4)

[...] não quero mais ter filho, eu pretendia ter outro, mas não quero mais ter filho[...].(P3)

[...] a gente não imaginava, nós estávamos totalmente despreparados. Para falar a verdade, a gente nem sabia que podia acontecer isso, já ouvimos falar, mas não sabia como funcionava, não tinha nada preparado, foi algo que pegou a gente [...]. (P10) 
A hospitalização do neonato é um momento de mudanças e de experiências múltiplas para os pais. O desconhecimento do ambiente hospitalar, das rotinas e cuidados, o estranhamento referente aos sons e ruídos da UN, o medo da perda e morte do filho, podem propiciar a insegurança e estresse familiar..$^{3-4}$

O planejamento e a expectativa relacionada a vinda do bebê modificou-se com o nascimento pré-termo e a internação do RN na UN. O tempo limitado para a adaptação psicológica, pode ocasionar um trauma devido à vulnerabilidade do quadro clínico ou estado de saúde da criança, mudando a idealização que se tinha de um bebê saudável para os sentimentos desafiados pela fase da internação. ${ }^{3}$

A jornada de trabalho desses pais foi um fator agravante para a sua presença de modo contínuo ou ampliado na UN. Embora no serviço investigado os pais tenham livre acesso à Unidade nas 24 horas do dia, destaca-se que o contato pai-filho, na maioria das vezes, deu-se no horário noturno em função do horário de trabalho dos participantes.

Foi muito turbulento o nascimento dele, queria poder acompanhar mais minha esposa nessa fase agora, nosso bebê, mas complicado também, meu horário de trabalho dificulta um pouco, só consigo vim a noite, aí sobra para ela. (P2)

A licença paternidade no Brasil é de apenas cinco dias, havendo ampliações para servidores públicos estaduais e federais de acordo com as legislações específicas. ${ }^{18}$ Este período de afastamento do serviço é considerado ainda um tempo muito curto quando verificado todos os benefícios deste momento pai-filho para o desenvolvimento e crescimento saudável da criança. $^{12}$ 
Inclusão e participação nos cuidados ao filho pré-termo na unidade neonatal: percepções.... | 8

A fé, a religião e a espiritualidade apareceram como recurso, apoio e estratégia para alguns pais. A confiança nos cuidados prestados pela equipe de saúde e o suporte emocional fornecido por estes profissionais facilitam o enfrentamento durante o processo de internação.

[...] tem que confiar nas enfermeiras e nos médicos, porque até a enfermeira falou "a gente aqui faz a nossa parte, mas quem manda lá em cima é Deus”. A gente reza aqui e vai embora [...]. (P9)

[...] Era só um milagre e a gente vê que pode crescer, esticar e ficar como um adulto nascer daquele tamanho [...]. (P10)

Apesar de terem sido surpreendidos por um estado inicial de choque pelo nascimento pré-termo do neonato e se sentirem impotentes pelo fato de o bebê estar na UN, reconheceram o momento/situação como aprendizado, e relataram estar otimistas em relação à alta.

[...] foi assustador, mas ao mesmo tempo é algo que a gente acaba aprendendo com a situação [...]. (P10)

Sei lá, está sendo meio frustrante, mas hoje conversei com a médica e já falaram que vão começar dar leite para o bebê e já animou bastante eu e ela. Logo estamos em casa. (P7)

A internação de um filho na UN repercute na dinâmica da família inteira. Situações como esta demandam a existência de uma rede de apoio que auxilie na permanência dos pais no hospital. A presença do companheiro durante todo o processo de internação da criança reforça as relações da nova família, devendo ser estimulada pela equipe de saúde. ${ }^{19}$

\section{O primeiro toque paterno}

A primeira visita dos pais é um momento de oportunidade para o profissional enfermeiro possibilitar a interação entre família, RN, equipe e o ambiente, reduzindo possíveis barreiras, frequentemente, encontradas por quem desconhece o ambiente da UN. Durante a internação do 
RN na UN, percebe-se que o pai deseja apropriar-se desta tarefa assumindo seu protagonismo e, geralmente, sua primeira aproximação com o filho é por meio do toque. Os pais deste estudo demonstraram o desejo de tocar no filho, porém o medo de machucar ou prejudicar o neonato intimidou e dificultou a aproximação.

[...] A enfermeira foi lá e me explicou "não pai, você tem que tocar nele, ele precisa te sentir, você passa o gelzinho, faz a higienização”. Ela me incentivou a tocar. (P3)

[...] A gente perguntou se poderia encostar nele porque não sabíamos, aí ela falou "pode por a mão" dai a gente foi lá, devagarzinho. (P4)

Em alguns casos, nota-se limitado incentivo ao primeiro toque ou ao toque por parte da equipe de saúde, não havendo planejamento, ensino do cuidado e intervenção que favoreçam um momento adequado para a inclusão do pai nos cuidados e aproximação com o filho.

Elas falaram [técnicas de enfermagem] que não podia, mas daí ela [a esposa] encostou e eu pensei: "se ela pode, eu também posso". Isso foi no segundo dia, ele agarrava minha mão [...] Foi uma sensação muito boa. (P10)

Fui tocar após 4 dias. Foi a enfermeira que pediu pra eu esperar pra tocar, por causa da pele que estava bem gelatinosa. (P11)

Neste âmbito, pode-se ressaltar que o toque é importante para ao processo de construção do vínculo com o RN, sendo que a equipe de saúde tem papel fundamental para o empoderamento do pai para esta atividade. ${ }^{4}$

Para os pais o toque teve diferentes significados, já que por intermédio dele pode-se concretizar sentimentos, percepções e funções paternas. Os que vivenciam a paternidade pela primeira vez descreveram que a sua inexperiência aumentava a insegurança no desempenho do papel paterno. Contudo, destacaram que na medida em que aprendiam e experienciavam o cuidado com o filho, tal sentimento era amenizado. 
Não toquei porque fiquei com medo de machucar, porque a gente tem uma força diferente com o neném, demorei uns 3 dias [...]. (P6)

Fui tocar agora domingo [1 mês depois] no dia dos pais. Tenho medo de tocar, é muito sensivel, a minha mulher toca, mas dá medo, porque é pequeninho e eu sou desastrado. Só coloquei um pouquinho a mão quando não tinha ninguém vendo, passei álcool na mão e tirei rápido. (P9)

[...] foi uma emoção muito linda, uma alegria, me desabei, a gente nunca tinha tido esse contato. (P6)

Após a recepção do pai dentro da UN, é possível uma maior aproximação aos aparelhos e dispositivos utilizados, inclusive a descrição das rotinas do setor, dos direitos e deveres paternos e a apresentação da equipe multiprofissional como um elo facilitador para a aproximação e cuidado com o filho. Deste modo, a equipe pode identificar e caracterizar as necessidades familiares, promovendo convívio acolhedor e afetivo. ${ }^{1,3-4}$

É considerável que os pais sejam encorajados e orientados a tocarem seus filhos para a formação do apego, recuperação e desenvolvimento do bebê e também para amenizar os sentimentos de impotência e insegurança do genitor diante da hospitalização e do distanciamento do filho. ${ }^{1,3-4}$

O toque realizado pelo pai pode contribuir para o conforto e evolução clínica do neonato, sendo ainda uma forma de empoderamento paterno. ${ }^{4}$

\section{Tornar-se pai: a participação e a inclusão do pai nos cuidados com o filho internado}

Com o estudo, percebeu-se que os pais demonstraram insegurança relacionada à fragilidade do bebê, preferindo que os cuidados com o $\mathrm{RN}$ fossem realizados pela equipe de saúde, por sentirem-se menos capacitados ou à vontade de realizá-los. 
11 | Carvalho E, Mafra PPOC, Schultz LF, Schumacher B, Aires LCP

Alguns dos participantes relataram carência de competências para a realização do cuidado, destacando as enfermeiras do setor dotadas de conhecimento e habilidades para que fizessem o trabalho do cuidado em lugar do genitor. Outros demonstraram ainda medo de atrapalhar o trabalho da equipe ou receio de transmitir alguma doença ao bebê.

[...] Agora, no momento, tenho muito medo de fazer alguma coisa de errado e, em vez de ajudar, prejudicar; então prefiro evitar, deixar pra quem tem conhecimento, quem sabe fazer, porque me sinto inseguro, é pequenininho, vou ter bastante tempo pra pegar. (P1)

$\mathrm{Na}$ verdade eu nem queria tocar, porque fiquei com medo do risco de infecção [...]. (P3)

Vi ela [técnica de enfermagem] colocar ali o leite. Se for preciso em último caso eu faria, mas se tiver gente pra fazer eu prefiro não fazer [...]. (P9)

A distinção de gênero nos cuidados com o neonato apresentou-se na fala de um pai participante deste estudo que disse "homem parece que não nasceu pra isso". A ideia de que somente a mãe pode prestar os cuidados com o RN precisa ser desmistificada pelo homem, a inclusão do pai durante a gestação e a sua participação ativa no período neonatal, bem como no pediátrico também deve ser considerada para que aconteça a formação do vínculo afetivo, do apego e das relações familiares. Os pais percebem a sua participação pouco importante para o $\mathrm{RN}$, considerando a mãe como centro exclusivo do cuidado com o bebê.

[...] Eu sei que é a minha esposa que tem que aprender [...]. (P6)

Não sei, homem parece que não nasceu pra isso, tem uns que fazem ali, ajudam a mulher tirar o leite, eu olho aquilo, não sei, acho estranho. (P9)

O vínculo entre pai e filho pode estar relacionado com as vivências que esse homem teve em sua própria infância, considerando sua cultura e princípios. ${ }^{4,5,20}$ A dinâmica e relação intrafamiliar irão contribuir em situações extremas, como na internação de um filho na UN.,11,21 
Durante a fase da internação, o pai torna-se mediador entre a mãe e o RN, ao mesmo tempo em que responde às demandas do filho, aprende a amadurecer, a tornar-se pai. ${ }^{12}$

A posição da sociedade em relação à participação do pai no cuidado e desenvolvimento do seu filho diferencia de uma cultura para a outra, às vezes não sendo bem construída e aceita, direcionada somente para a mãe, sendo esta o centro único do cuidado com o filho. ${ }^{4}$ Salientamos que toda forma de participação e inclusão paterna no processo do cuidar é fundamental, o toque, a conversa, a presença, as orientações, o incentivo e o cuidado físico propriamente dito.

De acordo com o MS, o contato pele a pele favorece vínculo afetivo, estabilidade térmica, estímulo à amamentação e o desenvolvimento do RN, entre outros. ${ }^{1}$ Considerado um cuidado, o MC também foi citado por dois pais como algo positivo, possibilitando o contato, aproximação e cuidado entre pai e filho. Entretanto, somente dois dos participantes relataram ter realizado o MC, o que pode estar relacionado com a própria prematuridade e condições clínicas do neonato, com as limitações da equipe de saúde sobre a explanação sobre a abrangência do Método, ou então com os medos e incertezas que foram destaque nos sentimentos apresentados pelos pais.

Dou leite, troco fralda, faço canguru, faço tudo que tem que fazer com ele [...]. (P5)

Dei leite e fiz canguru, mas demorou para eu fazer por conta da prematuridade [...]. (P11)

O MC pode conferir uma ambiguidade de sentimentos para os pais, que temem em segurar o seu filho, e que se fortalecem com este contato. ${ }^{13} \mathrm{O}$ sucesso do MC depende do suporte fornecido pela equipe de saúde, sendo as orientações da equipe multiprofissional determinantes para a segurança familiar neste cuidado. ${ }^{22}$ Apesar da importância do MC, estabelecido no Brasil há quase duas décadas, ainda existem particularidades restringentes à sua implementação. ${ }^{22}$ 
Estudos que abordam a participação paterna na saúde materno-infantil estão em crescente desenvolvimento, destacando-se que, para o homem, exercer a função paterna, é fundamental ampliar a autoconfiança, empoderamento, maturidade, vínculo familiar, responsabilidades e desmistificar a cultura que coloca somente a mãe como protagonista do cuidado. A construção do “tornar-se pai” precisa ser amplamente resignificada para além das condições biológicas e incluir, principalmente, mudanças culturais e práticas institucionais..$^{5,10,20}$

Embora a inclusão do pai nos cuidados com o bebê seja o foco deste estudo, lembramos que o cuidado de enfermagem deve ser centrado na família, objetivando o envolvimento de todos os membros que a família considerar significativos para a melhora do neonato durante a internação hospitalar.

\section{A equipe de saúde para o protagonismo paterno}

É primordial que a equipe multidisciplinar conheça e identifique os fatores que interferem na relação e construção afetiva do pai e filho. Observa-se que os genitores mais proativos ou que receberam auxílio e intervenções da equipe de saúde para realizar os cuidados com RN tem a equipe como aliadas durante a internação. Porém, os pais inseguros ou que não foram preparados e incluídos pela equipe de saúde para realização dos cuidados com o filho, estes, relataram dificuldade no acolhimento, na compreensão das informações e também nos momentos de cuidado ao filho. Ter protocolos nas instituições de saúde para a inclusão do pai no cuidado ao filho é importante para que as condutas e tomadas de decisões pela equipe de saúde não sejam divergentes.

Gostaria de realizar, não me deram oportunidade. Não sei, eu acho que como ele esta com os aparelhinhos lá ainda, o banhozinho de luz mais o acesso e a sondinha, eles devem pensar que eu não devo esta preparado, 
Inclusão e participação nos cuidados ao filho pré-termo na unidade neonatal: percepções.... | 14

por isso que não ofereceram para eu fazer uma troca de fralda ou algo assim, entendeu?[...]. (P3)

Sim, eles dão bastante liberdade, principalmente para mim, "pai quer pegar ela?”, não precisava nem falar, deixa que eu pego ela. (P6)

Tem aquela [técnica de enfermagem] que vem conversar, pergunta as coisas, ela te explica, tem vontade de explicar alguma coisa, a gente é curioso, a gente não tem noção. Ela incentiva: "olha pai, tem que acordar ela, para ela ficar ativa pra mamar bem”. E tem aquela que chega de manhã cedo e diz: "nem toca! Não tira o pano porque não pode pegar luz!”. A gente se sente impotente, não sabe o que fazer. (P2)

Os pais demonstraram interesse na inserção dos cuidados e interação com o filho, iniciativas e incentivos por parte da equipe de enfermagem colaboram ou dificultam a aplicabilidade do modelo assistencial que preconiza o MS e também para a implementação do MC no que se refere à inclusão e estimulação do pai neste contexto. Embora em alguns casos mostrassem limitações de interação entre pai e equipe, dificultando a ligação entre pai e RN, observam-se também pontos positivos destacados nas falas dos entrevistados. É extremamente importante que a equipe acolha os pais de modo que eles possam receber as informações pertinentes ao seu filho e que lhe disponibilizem a oportunidade de aproximação com o RN.,3-4

Foi muito bom, eles falaram o que tinha para falar, mas de uma forma para não assustar a gente, mas falaram tudo, todos os riscos. (P7)

A gente não pode reclamar, pois desde que chegamos, o atendimento foi bom, não deixa nada a desejar. Aqui na Neonatal, eles chegam, se apresentam, a médica vem... explicam tudo, tudo é bom. (P9)

A compreensão da equipe multiprofissional da UN, o conhecimento, as ações, intervenções e o favorecimento de um ambiente adequado são fundamentais para que os pais se 
sintam acolhidos e seguros, para exercitar o papel de "ser família” em um ambiente, mesmo que estranho. ${ }^{4}$ Embora os programas do MS voltados para a assistência ao RN e à família, no que se refere a construção de vínculos afetivos e apego, inclusão e ensino dos cuidados durante a hospitalização do neonato, verifica-se que o modelo biológico centrado na doença e na execução de técnicas ainda é realidade em algumas UN.111 Todavia, é preciso repensar o modelo assistencial prestado na UN, sendo o RN e sua família o centro da assistência, visando o acolhimento, promoção de vínculo afetivo, escuta adequada, inclusão, participação e ensino dos cuidados, informações e esclarecimento sobre dúvidas.

\section{Considerações finais}

Conhecer as percepções paternas sobre a sua inclusão e participação nos cuidados durante a internação do seu filho pré-termo na UN mostrou que as condições clínicas em que o RN se encontra podem influenciar no vínculo afetivo entre pai e filho. A presente pesquisa mostra que o desempenho da paternidade pode acontecer de forma positiva, se o pai contar com o apoio da equipe de enfermagem para exercer seu papel, para a aproximação com o seu filho, e mesmo para a sua inclusão nos cuidados como o RN de forma mais participativa.

Os profissionais de saúde precisam acolher, ensinar os cuidados, incluir, favorecer a aproximação do pai com o filho, atentar e intervir as suas necessidades para que a função paterna seja exercida no ambiente hospitalar, contribuindo para o cuidado e melhora do $\mathrm{RN}$, trazendo benefícios imediatos e futuros tanto para o bebê quanto para o pai.

O livre acesso dos pais à Unidade possibilita a familiarização com o processo de internação. É necessário que o profissional de Enfermagem desenvolva um olhar atento, possibilitando a inserção do pai nos cuidados ao seu filho. O Cuidado Centrado na Família, de forma integral e individualizado deve ser praticado desde a formação acadêmica destes profissionais de saúde. 
Inclusão e participação nos cuidados ao filho pré-termo na unidade neonatal: percepções.... | 16

As limitações deste estudo remetem à necessidade de investigar também as percepções dos profissionais de saúde da UN sobre a importância da participação do pai nestes cuidados. Talvez, respondendo a esta lacuna, seja possível traçar estratégias para que a atuação paterna ocorra de forma inclusiva.

\section{Referências}

1. Ministério da Saúde (BR), Secretaria de Atenção à Saúde. Atenção humanizada ao recém-nascido: Método Canguru. Manual técnico [Internet]. 3를 ed. Brasília (DF): Ministério da Saúde; 2017 [acesso em 2019 jan 09]. $342 \quad$ p. $\quad$ Disponível em: http://bvsms.saude.gov.br/bvs/publicacoes/atencao_humanizada_metodo_canguru_manual_3ed.pdf

2. World Health Organization [Organização Mundial da Saúde]. WHO recommendations on interventions to improve preterm birth outcomes [Internet]. Genebra: Organização Mundial da Saúde; 2015 [acesso em 2018 nov 06]. Disponível em: http://apps.who.int/iris/bitstream/handle/10665/183037/?sequence=1

3. Borges KI, Santana JO, Souza DA, Silva VCE, Pinto KRTF, Zani AV. Vivências do pai/homem no cuidado ao filho prematuro hospitalizado. REME Rev Min Enferm [Internet]. 2018 [acesso em 2019 jan 09];22:e-1141. Disponível em: http://reme.org.br/artigo/detalhes/1280doi: 10.5935/1415-2762.20180071

4. Soares RLSF, Christoffel MM, Rodrigues EC, Machado MED, Cunha AL. Ser pai de recém-nascido prematuro na unidade de terapia intensiva neonatal: da parentalidade a paternidade. Esc Anna Nery RevEnferm [Internet]. 2015 [acesso em 2017 dez 13];19(3):409-16. Disponível em: http://www.scielo.br/pdf/ean/v19n3/1414-8145-ean-19-03-0409.pdfdoi: 10.5935/1414-8145.20150054

5. Brasil. Presidência da República. Lei n. 8.069, de 13 de julho de 1990. Dispõe sobre o Estatuto da Criança e do Adolescente (ECA) e dá outras providências [Internet]. 1990 [acesso em 2017 dez 11]. Disponível em: http://www.planalto.gov.br/Ccivil_03/leis/L8069.htm

6. Matos MG, Magalhães AS, Féres-Carneiro T, Machado RN. Construindo o vínculo pai-bebê: a experiência dos pais.Psico USF [Internet]. 2017 maio-ago [acesso em 2017 dez 12];22(2):261-71. Disponível em: $\quad$ http://www.scielo.br/pdf/pusf/v22n2/2175-3563-pusf-22-02-00261.pdfdoi: $\quad$ 10.1590/141382712017220206

7. Holanda SM, Castro RCMB, Aquin PS, Pinheiro AKB, Lopes LG, Martins ES. Influência da participação do companheiro no pré-natal: satisfação de primíparas quanto ao apoio no parto. Texto \& Contexto Enferm [Internet]. 2018 [acesso em 2019 jan 09];27(2):e3800016. Disponível em: 
8. Brasil.Presidência da República. Lei n. 11.108, de 7 de abril de 2005.Altera a Lei 8.080, de 19 de setembro de 1990, para garantir as parturientes o direito à presença de acompanhante durante o trabalho de parto, parto e pós-parto imediato, no âmbito do Sistema Único de Saúde (SUS). Diário Oficial da União, Brasília (DF); 2005 abr08. Seção 1, p.1.

9. Bernardi D. Paternidade e cuidado: "novos conceitos", velhos discursos. Psicol Rev [Internet]. 2017[acesso em 2019 jan05]26(1):59-80. Disponível em: https://revistas.pucsp.br/psicorevista/article/view/28743/23329.pdf

10. Antunes JT, Pereira LB, Vieira MA, Lima CA. Presença paterna na sala de parto: expectativas, sentimentos e significados durante o nascimento. RevEnferm UFSM [Internet] 2014 jul-set [acesso em 2017 dez 13];4(3):536-45. Disponível em: https://periodicos.ufsm.br/reufsm/article/view/12515doi:10.5902/2179769212515

11. Carvalho LS, Pereira CMC.As reações psicológicas dos pais frente à hospitalização do bebê prematuro na UTI neonatal. Rev SBPH [Internet]. 2017 jul-dez [acessoem 2019 jan 09];20(2):101-22. Disponívelem:http://pepsic.bvsalud.org/pdf/rsbph/v20n2/v20n2a07.pdf

12. Strapasson MR, Lima BSS, Ferreira GE, Oliveira GC, Bonilha ALL, Paz PO. Percepção do pai acerca da paternidade no alojamento conjunto. RevEnferm UFSM [Internet]. 2017 jan-fev [acesso em $2017 \mathrm{dez}$ 13];7(1):80-9. Disponível em: https://periodicos.ufsm.br/reufsm/article/view/22295/pdf doi: $10.5902 / 2179769222295$

13. Hagen IH, Iversen VC, Svindseth MF.Differences and similarities between mothers and fathers of premature children: a qualitative study of parents' coping experiences in a neonatal intensive care unit. BMC Pediatrics [Internet]. 2016 [acesso em 2019 jan 09];16(92):1-9. Disponível em: https://bmcpediatr.biomedcentral.com/track/pdf/10.1186/s12887-016-0631-9 doi:10.1186/s12887-016-06319

14. Brasil. Ministério da Saúde. Portaria n. 930/GM, de 10 de maio de2012. Define as diretrizes e objetivos para a organização da atenção integral e humanizada ao recém-nascido grave ou potencialmente gravee os critérios de classificação e habilitação de leitos de Unidade Neonatal no âmbito do Sistema Único de Saúde (SUS). Diário Oficial União, Brasília (DF); 2012 maio 11. Seção 1, p. 138.

15. Brasil. Ministério da Saúde. Portaria n. 3.389/GM, de 30 de dezembro de 2013. Altera, acresce e revoga dispositivos da Portaria n 930/GM/MS, de 10 maio de 2012, que define as diretrizes e objetivos para a organização da atenção integral e humanizada ao recém-nascido grave ou potencialmente grave e os critérios de classificação e habilitação de leitos de Unidade Neonatal no âmbito do Sistema Único de Saúde(SUS). Diário Oficial da União, Brasília (DF); 2013 dez. 31. Seção 1, p. 54. 
Inclusão e participação nos cuidados ao filho pré-termo na unidade neonatal: percepções.... $\mid 18$

16. Nascimento LCN, Souza TV, Oliveira ICS, Moraes JRMM, Aguiar RCB, Silva LF. Saturação teórica em pesquisa qualitativa: relato de experiência na entrevista com escolares. Rev Bras Enferm [Internet]. 2018 jan-fev [acesso em 2019 jan 09];71(1):228-33. Disponível em: http://www.scielo.br/pdf/reben/v71n1/pt_0034-7167-reben-71-01-0228.pdf doi: 10.1590/0034-7167-20160616

17. Minayo MCS. O desafio do conhecimento: pesquisa qualitativa em saúde. São Paulo (SP): Hucitec; 2013.

18. Brasil. Constituição (1988). Artigo $7^{\circ}$, XIX e art. 10, $§ 1^{\circ}$, do Ato das Disposições Constitucionais Transitórias [Internet]. 1988 [acesso em 2019 jan 09]. Disponível em: https://www2.senado.leg.br/bdsf/bitstream/handle/id/518231/CF88_Livro_EC91_2016.pdf

19. Testoni TT, Aires LCP.O Método Canguru como um veículo para o empoderamento materno. REFACS [Internet]. 2018 [acesso em 2019 jan 09];6(2):611-19. Disponível em: http://seer.uftm.edu.br/revistaeletronica/index.php/refacs/article/view/2957/pdf doi: 10.18554/refacs.v6i0.2957

20. Ribeiro CR, Gomes R, Moreira MCN. A paternidade e a parentalidade como questões de saúde frente aos rearranjos de gênero. Ciênc Saúde Colet [Internet]. 2015 nov [acesso em 2017 dez 20];20(11):3589-98. Disponível em: http://www.scielo.br/pdf/csc/v20n11/1413-8123-csc-20-11-3589.pdfdoi: 10.1590/1413812320152011.19252014

21. Marski BSL, Custodio N, Abreu FCP, Melo DF, Wernet M. Alta hospitalar do recém-nascido prematuro: experiência do pai. RevBrasEnferm[Internet]. 2016 mar-abr [acesso em 2017 dez 13];69(2):2218. Disponível em: http://www.scielo.br/pdf/reben/v69n2/0034-7167-reben-69-02-0221.pdfdoi: 10.1590/00347167.2016690203i

22. Aires LCP, Santos EKA, Costa R, Borck M, Custódio ZAO. Seguimento do bebê na atenção básica: interface com a terceira etapa do Método Canguru. Rev Gaúcha Enferm [Internet]. 2015 [acesso em 2017 dez 22];36(esp):224-32. Disponível em:http://www.scielo.br/pdf/rgenf/v36nspe/0102-6933-rgenf-36-spe0224.pdfdoi: 10.1590/1983-1447.2015.esp.56805

\section{Autor correspondente}

Eilane Carvalho

E-mail:eilanecarvalho.nane@gmail.com

Endereço: Rua Uirapuru 149, Aventureiro, Joinville - SC/ Brasil

CEP:89225-680

\section{Contribuições de Autoria}

1 - Carvalho E 
19 | Carvalho E, Mafra PPOC, Schultz LF, Schumacher B, Aires LCP

Concepção, planejamento do projeto de pesquisa, obtenção, análise e interpretação dos dados, redação.

2 -Mafra PPOC

Concepção, planejamento do projeto de pesquisa, obtenção, análise e interpretação dos dados, redação.

3 -Schultz LF

Concepção, planejamento do projeto de pesquisa, análise e interpretação dos dados, redação e revisão crítica.

4 -Schumacher B

Planejamento do projeto de pesquisa e revisão crítica.

5 -Aires LCP

Concepção, planejamento do projeto de pesquisa, análise e interpretação dos dados, redação e revisão crítica.

\section{Como citar este artigo}

Carvalho E, Mafra PPOC, Schultz LF, Schumacher B, Aires LCP. Inclusão e participação nos cuidados ao filho pré-termo na unidade neonatal: percepções paternas. Rev. Enferm. UFSM. 2019 [Acesso em: Anos Mês Dia];vol 31: P1-P19. DOI:https://doi.org/10.5902/2179769231121 